\title{
Study of eight cases of cancer in 426 rheumatoid arthritis patients treated with methotrexate
}

Christophe Bologna, Marie-Christinne Picot, Christian Jorgensen, Philippe Viu, Regis Verdier, Jacques Sany

\begin{abstract}
Objective-To report cancer cases in 426 rheumatoid arthritis patients treated with methotrexate, and determine whether there was an increased incidence of cancer compared with patients never treated with methotrexate (rheumatoid controls) and to the whole regional population.

Methods-The duration of methotrexate treatment was 37.4 (SD 27.9) months. This population was compared with 420 rheumatoid arthritis controls and with a regional population of 812344 people. Life table analysis was performed to compare the cancer incidence in the two rheumatoid populations. Adjustment for potentially confounding factors was done. The indirect standardisation method was used to compare each rheumatoid population with the regional population.
\end{abstract}

Results-Eight cases of cancer (1.88\%; 4.04 cases $/ 1000$ person years) were diagnosed in the methotrexate population $v$ six $(1.43 \% ; 58.8$ cases/1000 person years) in the rheumatoid controls. The life table method showed a higher incidence of cancer in the rheumatoid controls $(P=$ 0.0001). In a multivariate analysis (Cox model), the only significant factor explaining this difference in the cancer incidence was age $(P=0.02)$. In the regional population there were 6418 new cases of cancer $(0.79 \% ; 2.85$ cases $/ 1000$ person years). By the indirect standardisation method, the ratio of observed cases to expected cases of cancer in each of the rheumatoid populations was not significantly different from 1.

Conclusions-In these eight cases, methotrexate was not found to be responsible for generating cancers. However, because of data regarding lymphomas and methotrexate, and because of the short follow up, especially in the control group, longer prospective studies are warranted.

(Ann Rheum Dis 1997;56:97-102)

Weekly low dose methotrexate is increasingly used in the treatment of various conditions, particularly rheumatoid arthritis. However, methotrexate is an antifolate antimetabolite. The oncogenicity of methotrexate is still controversial because of the lack of large series of rheumatoid patients with long term follow up, and because of an increased incidence of lymphomas due to rheumatoid arthritis. ${ }^{1-4}$ Moreover, other factors must be considered, such as the presence or absence of Sjögren syndrome and the previous or concurrent use of cytotoxic drugs (cyclophosphamide, azathioprine) - thus it was shown in a 20 year follow up study of 404 rheumatoid patients (202 treated and 202 not treated with azathioprine) that the risk of lymphoma was twofold greater in the group which received azathioprine. ${ }^{5}$

Case studies of cancer diagnosed during methotrexate treatment in rheumatoid patients have already been reported. The cancers are mainly lymphomas and pseudolymphomas. ${ }^{6-19}$ The causative role of methotrexate is still difficult to establish as coincidences cannot be ruled out, but regression of tumours after methotrexate withdrawal has been described. ${ }^{9131920}$

We have undertaken a long term retrospective study of 426 rheumatoid arthritis patients treated with methotrexate and followed up in our unit. The case notes of patients diagnosed with cancer during the follow up period were reviewed. To determine whether there was an increased incidence of cancer in methotrexate treated rheumatoid patients, we compared the incidence of cancer in this group with that of rheumatoid patients never treated with this drug (rheumatoid arthritis controls) and with the whole regional population.

\section{Methods}

PATIENTS

All patients were recruited in our unit as inpatients or outpatients and fulfilled the American College of Rheumatology criteria for rheumatoid arthritis. ${ }^{21}$ The case notes of the patients with a diagnosis of cancer were carefully reviewed to determine the diagnosis, particular attention being paid to the histopathological results.

\section{Methotrexate treated patients}

The decision to use methotrexate was made by the physician in charge of the patient during hospital admission. Methotrexate was always given in a single weekly dose, by either oral or intramuscular route. Four hundred and sixty nine rheumatoid arthritis patients were treated with methotrexate between 1 January 1985 and 31 March 1994. The date of evaluation was 1 November 1994. For all patients except $11(2.3 \%)$ lost to follow up we had recent medical information from physical examinations (performed less than six months before the date of evaluation). We recorded information on medical and surgical history, current treatment, and the time and reason for
Accepted for publication 24 October 1996 
Table 1 Characteristics of 426 rheumatoid arthritis (RA) patients treated with methotrexate (MTX) and 420 not treated with MTX. Values are means (SD) or range

\begin{tabular}{|c|c|c|c|c|c|}
\hline & $M T X$ group $(n=426)$ & Range or $\%$ & Controls $(n=420)$ & Range or \% & $P^{*}$ \\
\hline $\operatorname{Sex}(M / F)$ & $78 / 348$ & & $101 / 319$ & & 0.04 \\
\hline Age (years) & $50.8(12.3)$ & 20 to 78 & $59.9(14.9)$ & 16 to 87 & 0.0001 \\
\hline RA duration (years) & $13.3(8.1)$ & 1 to 41 & $10.2(10.6)$ & 0.13 to 52 & 0.0001 \\
\hline $\mathrm{RF}$ & 349 & $81.9 \%$ & 149 & $43.7 \%$ & $<0.001$ \\
\hline MTX weekly dose (mg) & $9.9(1.5)$ & 2.5 to 15 & - & - & - \\
\hline MTX duration (months) & $37.4(27.9)$ & 1 to 105 & - & - & - \\
\hline Swollen joints & $\begin{array}{l}7.7(4.9) \\
(\mathrm{n}=398)\end{array}$ & 0 to 35 & $\begin{array}{l}5.1(5.1) \\
(\mathrm{n}=367)\end{array}$ & 0 to 44 & 0.0001 \\
\hline Painful joints & $\begin{array}{l}8.6(4.9) \\
(\mathrm{n}=399)\end{array}$ & 0 to 32 & $\begin{array}{l}7.5(5.7) \\
(\mathrm{n}=367)\end{array}$ & 0 to 31 & 0.0001 \\
\hline Ritchie's index & $\begin{array}{l}13.7(9.0) \\
(\mathrm{n}=396)\end{array}$ & 0 to 60 & $\begin{array}{l}9.0(8.4) \\
(n=332)\end{array}$ & 0 to 74 & 0.0001 \\
\hline Morning stiffness (min) & $\begin{array}{l}102(88) \\
(\mathrm{n}=400)\end{array}$ & 0 to 540 & $\begin{array}{l}63(81) \\
(\mathrm{n}=350)\end{array}$ & 0 to 720 & 0.0001 \\
\hline Larsen's score & $\begin{array}{l}40.3(31.4) \\
(\mathrm{n}=119)\end{array}$ & $0-122$ & $\begin{array}{l}37.8(34.9) \\
(\mathrm{n}=295)\end{array}$ & 0 to 150 & NS \\
\hline $\operatorname{ESR}(\mathrm{mm} / \mathrm{h})$ & $\begin{array}{l}47.2(29.8) \\
(\mathrm{n}=405)\end{array}$ & 2 to 139 & $\begin{array}{l}34(26.4) \\
(\mathrm{n}=364)\end{array}$ & 1 to 134 & 0.0001 \\
\hline $\mathrm{CRP}\left(\mathrm{mg} \mathrm{l}^{-1}\right)$ & $\begin{array}{l}42.4(95.9) \\
(\mathrm{n}=133)\end{array}$ & 1 to 750 & $\begin{array}{l}31.9(45.1) \\
(\mathrm{n}=321)\end{array}$ & 0 to 300 & NS \\
\hline Haemoglobin $\left(\mathrm{g} \mathrm{dl}^{-1}\right)$ & $\begin{array}{l}11.9 \\
(\mathrm{n}=363)\end{array}$ & 7.3 to 17.1 & $\begin{array}{l}12.5(1.6) \\
(\mathrm{n}=360)\end{array}$ & 8.4 to 18.3 & 0.0001 \\
\hline Platelets $\left(\mathrm{mm}^{-3}\right)$ & $\begin{array}{l}344(117) \\
(\mathrm{n}=357)\end{array}$ & 117 to 851 & $\begin{array}{l}309(103) \\
(\mathrm{n}=356)\end{array}$ & 98 to 796 & 0.0001 \\
\hline
\end{tabular}

RF, rheumatoid factor positivity defined as $\geq 40$ IU litre $^{-1}$, laser nephelometry; ESR, erythrocyte sedimentation rate;

CRP, $C$ reactive protein

*Mann-Whitney U test

methotrexate withdrawal. If methotrexate was still being used, we asked particularly about side effects and the effect of folic acid if prescribed. The analysis was performed on patients for whom we had at least 12 months of follow up data $(n=426)$, regardless of the duration of methotrexate treatment. The mean follow up was 4.65 (SD 2.34) years (range 1.07 to 9.98 ), with a total of 1981.15 person-years.

\section{Rheumatoid arthritis controls}

All rheumatoid arthritis patients admitted as inpatients to the unit between 1 January 1990 and 1 November 1994 and never treated with methotrexate were included in the control group ( $n=420$ rheumatoid arthritis patients). A register of admissions is available but there was no register for patients who attended the unit but who were not admitted. The starting date for the follow up of the control patients was arbitrarily defined as the date of the first hospital admission between 1 January 1990 and 1 November 1994. Four hundred and twenty patients were available for analysis. The mean (SD) number of hospital admissions for these patients during this period was $1.7(1.3)$. One hundred and ninety nine patients were seen only once as inpatients. For patients who were admitted more than once during this period $(n=229)$, the mean follow up duration was $1.0(0.74)$ years, with a total of 102 person-years $(P=0.0001$, compared with the methotrexate treated group). The present analysis mainly represents a cross sectional study of the incidence of cancers in the rheumatoid population not treated with methotrexate.

REGIONAL POPULATION

Data were obtained from the cancer registry based on the years 1991 to $1992 .^{22}$ All of these patients lived in the area around Montpellier (Department of Herault, France).
STATISTICAL ANALYSIS

The number of newly diagnosed cancers in the rheumatoid arthritis controls and the regional population was compared with that of the methotrexate treated rheumatoid population using the life table (actuarial) method. We then compared the demographic, clinical, biological, and radiological data at baseline between the two groups $\left(\chi^{2}\right.$ and Wilcoxon two sample test). Survival estimates were again performed adjusting for any potentially confounding factors found to have a significantly different distribution between the two rheumatoid populations. Comparison of the cancer incidence in the two rheumatoid populations with the incidence in the regional population was performed using an age adjusted incidence method on the regional population (Languedoc-Roussillon, 1991 to 1992). The reference population was the regional population. The ratios of the number of observed cases reported to the number of expected cases were compared to 1 by a $\chi^{2}$ test. $P$ values of 0.05 were considered significant.

\section{Results}

CHARACTERISTICS OF RHEUMATOID PATIENTS TREATED OR NOT WITH METHOTREXATE

The main characteristics of the methotrexate treated rheumatoid patients $(n=426)$ are presented in table 1 . Previous disease modifying treatments (DMARD) were stopped one month before introducing methotrexate, except in 54 patients whose previous DMARD were continued with the methotrexate, or for whom another DMARD was introduced with the methotrexate (mainly hydroxychloroquine and rarely sulphasalazine). Three patients took immunosuppressive drugs, that is, cyclophosphamide $(n=2)$ and azathioprine $(n=1)$, before methotrexate; 141 patients took prednisone at the onset of methotrexate [14.1 (SD 5.8) $\mathrm{mg} / \mathrm{d}$ ] and 63 took concomitant folic acid [17.1 (9.1) mg/week]. 
Table 2 Characteristics of methotrexate (MTX) treated rheumatoid arthritis (RA) patients and of RA controls who developed cancers

\begin{tabular}{|c|c|c|c|c|c|c|c|c|}
\hline Patient & Cancer & $A g e^{a}$ & $\operatorname{Sex}$ & $\begin{array}{l}R A \text { duration } \\
\text { (years) }\end{array}$ & Sjögren syndrome & Treatment & $\begin{array}{l}\text { Evolution of } \\
\text { cancer }\end{array}$ & $\begin{array}{l}\text { Follow up } p^{b} \\
\text { (months) }\end{array}$ \\
\hline 1 & melanoma & 62 & $\mathrm{~F}$ & 30 & - & surgery & remission & 50 \\
\hline 2 & lung $^{\mathrm{c}}$ & 66 & $M$ & 9 & + & surgery & death & - \\
\hline 3 & $\mathrm{NHL}^{\mathrm{d}}$ & 66 & $\mathrm{~F}$ & 14 & + & chemotherapy & remission & 71 \\
\hline 4 & Hodgkin & 56 & $\mathrm{M}$ & 4.5 & - & radio- + chemotherapy & remisssion & 65 \\
\hline 5 & gastric $^{\mathrm{e}}$ & 69 & $\mathrm{M}$ & 4 & + & surgery & death & - \\
\hline 6 & cervix & 44 & $\mathrm{~F}$ & 21 & - & radiotherapy + surgery & remission & 33 \\
\hline 7 & womb & 46 & $\mathrm{~F}$ & 1 & + & surgery & remission & 24 \\
\hline 8 & $\begin{array}{l}\text { Paget of } \\
\text { breast }\end{array}$ & 56 & $\mathrm{~F}$ & 4 & - & radiotherapy + surgery & remission & 47 \\
\hline 9 & cervix & 38 & $\mathrm{~F}$ & 20 & - & surgery & remission & 66 \\
\hline 10 & NHL & 37 & $\mathrm{~F}$ & 19 & + & chemotherapy & recurrence & 60 \\
\hline 11 & prostatic & 68 & M & 10 & - & $\begin{array}{l}\text { surgery }+ \\
\text { hormone therapy }\end{array}$ & $\operatorname{lost}^{\mathrm{g}}$ & - \\
\hline 12 & $\mathrm{CML}^{\mathrm{f}}$ & 70 & $\mathrm{~F}$ & 21 & + & chemotherapy & death & 14 \\
\hline 13 & Waldenström & 79 & $\mathrm{~F}$ & 10 & + & corticosteroids & remission & 36 \\
\hline 14 & gastric & 69 & $\mathrm{~F}$ & 3 & - & surgery & $\operatorname{lost}^{\mathrm{g}}$ & - \\
\hline
\end{tabular}

Patients 1 to 8: MTX treated patients; patients 9 to 14 : control patients; ${ }^{a}$ age at diagnosis of cancer; ${ }^{b}$ after diagnosis of cancer; tobacco abuse, 50 pack-years; ${ }^{d}$ non-Hodgkin lymphoma, centroblastic, centrocytic follicular, in lymph nodes and thyroid, with Hashimoto thyroiditis; ${ }^{\mathrm{e}} 10$ years before, $2 / 3$ gastrectomy for peptic ulcer; ${ }^{\mathrm{f}}$ chronic myeloid leukemia; ${ }^{\mathrm{g}}$ lost to follow up

The main characteristics of the rheumatoid controls $(n=420)$ are also presented in table 1 . Five control rheumatoid patients $(1.2 \%)$ previously received an immunosuppressive drug: cyclophosphamide $(\mathrm{n}=2)$ and azathioprine $(\mathrm{n}$ $=3)$. Azathioprine was given to control rheumatoid activity; cyclophosphamide was given in one case for rheumatoid vasculitis associated with glomerulonephritis, and in the other for pulmonary fibrosis. Only one patient with cancer (gastric epithelioma) was previously treated with cyclophosphamide (for vasculitis and glomerulonephritis).

CANCERS IN RHEUMATOID PATIENTS TREATED WITH METHOTREXATE

We recorded eight cases of neoplasia out of 426 rheumatoid patients treated with methotrexate $(1.88 \%$, or 4.04 cases 1000 person years of observation). The characteristics of these patients are given in tables 2 and 3. None of these eight patients had previously received any immunosuppressive drug. Two patients died. The other patients are still considered to be in remission [follow up of 48.3 (18.1) months].

COMPARISONS WITH RHEUMATOID CONTROLS

Out of the 420 rheumatoid control patients, we detected six new cancer cases $(1.43 \%$, or 58.8 cases/1000 person years of observation). The characteristics of these patients are given in table 2. The mean follow up for these six patients after the diagnosis of cancer was 44 (23.8) months. No differences were noted in the demographic data between patients with cancer in the methotrexate treated population and those with cancer in the control rheumatoid population (age at diagnosis of cancer, sex, presence or absence of Sjögren syndrome, duration of rheumatoid arthritis at diagnosis of cancer) ( $\chi^{2}$ test and MannWhitney U test, data not shown).

The life table analysis showed that there was a significantly higher incidence of cancer in the control group ( $P=0.0001$, log-rank test) (see the figure, showing the cancer-free survival curves). We looked at potential confounding factors to explain the difference in cancer incidence. As shown in table 1, there are many fac-

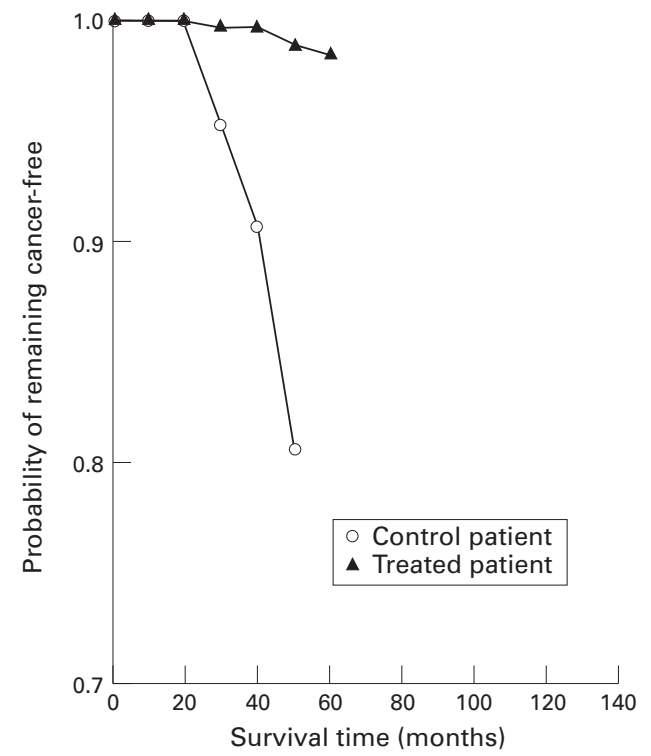

Cancer-free survival curves (event $=$ occurrence of a cancer) in the two rheumatoid populations: treated with methotrexate $(n=426)$ and controls never treated with methotrexate $(n=420)$. The difference between the curves is significant $(P=0.0001, \log$-rank $)$, indicating a higher occurrence of cancers in the rheumatoid controls.

tors that were differently distributed between the two rheumatoid groups. The lifetest procedure failed to show any influence of sex or rheumatoid factor positivity in the occurrence of cancer when comparing the two rheumatoid populations. The variables found to have a significantly different distribution between the two rheumatoid populations (table 1) were introduced in the multivariate analysis (Cox model). We noted that the only significant factor was age $(P=0.02)$; methotrexate treatment duration was not significant $(P=0.22)$. This result means that the difference observed in the survival curves between the two rheumatoid populations is explained by a difference in age distribution.

There was no significant difference in the frequency of immunosuppressive drugs used in the two populations of patients: $3 / 426$ or $0.7 \%$ 
Table 3 Characteristics of methotrexate (MTX) treatment in the eight rheumatoid arthritis patients who developed cancers under treatment

\begin{tabular}{lllll}
\hline Patient & Cancer & $\begin{array}{l}\text { Intermittent withdrawal } \\
(\text { month })\end{array}$ & $\begin{array}{l}\text { MTX total dose } \\
(\mathrm{mg})\end{array}$ & MTX \\
\hline 1 & melanoma & 1 & 2790 & continued \\
2 & lung & - & 300 & stopped \\
3 & NHL & 29 & 2050 & continued \\
4 & Hodgkin & - & 240 & stopped \\
5 & gastric & - & 630 & stopped \\
5 & cervix & 0 & 215 & continued \\
6 & corpus uteri & 0 & 2150 & continued \\
7 & Paget of breast & 0 & 1330 & \\
8 & & &
\end{tabular}

in the methotrexate population versus $5 / 420$ or $1.2 \%$ in the control population $(\mathrm{P}=0.5)$.

COMPARISONS WITH THE REGIONAL POPULATION During the years 1991 to 1992,6418 cases of cancer were reported out of a mean regional population of 812344 people $(0.79 \%$, or 2.85 cases/1000 person years). Using the indirect standardisation method (reference population $=$ regional population), in the methotrexate group we noted a ratio of eight observed cases for 8.31 expected cases $\left(\chi^{2}=0.011, \mathrm{NS}\right)$. Similarly, in the rheumatoid controls the ratio was six observed cases for 3.4 expected $\left(\chi^{2}=1.98\right.$, NS). Therefore, adjusting for age, there was no significant difference in the frequency of cancer in the two rheumatoid populations compared with the regional survey.

\section{Discussion}

We found a total of eight cancers in 426 rheumatoid arthritis patients treated with methotrexate [cumulative frequency of $1.88 \%$ during a mean follow up of 4.65 (2.34) years]. As in this study, previously reported cancers have been heterogeneous: thymoma, ${ }^{6}$ acute and chronic leukaemia, ${ }^{723}$ bladder urothelial cancer, mediastinal teratoma, and squamous cell carcinoma of the thoracic skin. ${ }^{8}$ However, non-Hodgkin lymphoma is the main type of cancer reported ${ }^{9-1520}{ }^{23}$ (table 4 ). These cases must be differentiated from the exceptional case of pseudolymphoma. ${ }^{16}$ We only observed one case of non-Hodgkin lymphoma in 426 rheumatoid arthritis patients treated with methotrexate; it should be stressed that in this patient - suffering from Sjögren syndrome and Hashimoto thyroiditis-it was a nodal and extranodal lymphoma localised in the thyroid gland. The incidence of non-Hodgkin lymphoma in patients with Sjögren syndrome is 43.8 -fold greater than that expected in the general population. ${ }^{25}$ Furthermore, the relative risk of malignant lymphoma of the thyroid gland in chronic lymphocytic thyroiditis is $67 .^{26}$ Consequently, the responsibility of methotrexate treatment in the development of this lymphoma is very difficult to establish.

The more frequent association of nonHodgkin lymphoma and methotrexate treatment in rheumatoid arthritis patients is troublesome. The main argument implicating methotrexate in the appearance of lymphomas in rheumatoid arthritis patients is the complete regression of the tumour after methotrexate withdrawal alone. ${ }^{9131920}$ In the latter case, ${ }^{20}$ when methotrexate was reintroduced because of the evolution of rheumatoid arthritis, there was a recurrence of the tumour. Furthermore, Kamel et al ${ }^{27}$ reported 15 cases of lymphoma in rheumatoid arthritis and three in dermatomyositis, of whom 33\% $(n=6)$ presented with an EBV infection. Five of these six patients were treated with methotrexate, and the authors suggested that methotrexate as an immunosuppressor could have contributed to the development of these EBV associated lymphomas. $^{27}$

An increased incidence of non-Hodgkin lymphomas in a rheumatoid arthritis population has been reported, ${ }^{1-4}$ the relative risk being $13^{4}$ and $24.1,{ }^{2}$ without any implication of cytotoxic drugs. ${ }^{2328}$ This increased incidence of lymphomas in rheumatoid arthritis could explain the appearance of lymphomas in rheumatoid patients treated with methotrexate. Another argument against a causative role of methotrexate is that it did not augment the frequency of sister chromatid exchange (a sensitive method of detecting the mutagenicity of a molecule) in eight psoriasis patients treated for two to 10 months. ${ }^{29}$

We found a higher incidence of cancer ( $P=$ 0.0001 ) in the rheumatoid controls, but this difference disappeared when an adjustment for age was made. Nevertheless, there was still no increase in the frequency of cancer in the methotrexate treated group, contrary to what might be feared when using a drug with antifolate properties. The frequency of cancer in the rheumatoid controls could have been underestimated as not all the outpatient data were systematically available and no special attention was paid to these patients, in contrast

Table 4 Characteristics of 11 rheumatoid arthritis patients treated with methotrexate (MTX) who developed non-Hodgkin lymphoma

\begin{tabular}{|c|c|c|c|c|c|c|c|c|c|c|c|}
\hline Reference & Sex & Age & Sjögren syndrome & $E B V$ & Histology & Grade & $\begin{array}{l}\text { MTX total dose } \\
(m g)\end{array}$ & $M T X$ & Treatment & Evolution & $\begin{array}{l}\text { Follow up } \\
\text { (months) }\end{array}$ \\
\hline 9 & $\mathrm{~F}$ & 83 & + & ND & $\mathrm{T}$ & low & $?$ & stopped & none & remission & 24 \\
\hline 10 & $\mathrm{~F}$ & 51 & - & ND & B & low & 990 & ? & chemotherapy & remission & ? \\
\hline 11 & $\mathrm{~F}$ & 55 & - & + & $\mathrm{T}$ & high & ? & ? & chemotherapy & death & - \\
\hline 12 & $\mathrm{~F}$ & 47 & - & ND & B & low & 900 & stopped & chemotherapy & remission & 30 \\
\hline 13 & $\mathrm{~F}$ & 86 & ? & + & B & high & ? & stopped & none & remission & 16 \\
\hline 14 & $\mathrm{~F}$ & 72 & ? & + & $?$ & $?$ & 330 & continued & radiotherapy & remission & $?$ \\
\hline 15 & M & 44 & - & ND & B & low & 748 & ? & chemotherapy & ongoing ${ }^{\star}$ & ? \\
\hline 15 & $M$ & 48 & - & + & B & low & 438 & ? & chemotherapy & death & - \\
\hline 17 & $\mathrm{~F}$ & 57 & - & + & B & ? & ? & stopped & none & remission & 48 \\
\hline 18 & $\mathrm{~F}$ & 64 & - & ND & B & ? & 560 & stopped & none & death & - \\
\hline 21 & M & 40 & - & ND & $\mathrm{B}$ & high & $?$ & ? & chemotherapy & death & 1 \\
\hline 22 & M & 70 & - & ND & B & low & 470 & stopped & chemotherapy & stability & 5 \\
\hline Personal & M & 66 & + & ND & ? & low & 2050 & continued & chemotherapy & remission & 71 \\
\hline
\end{tabular}


to the methotrexate treated rheumatoid patients who have always been carefully followed up in our unit. Furthermore, in the analysis we decided to consider patients treated with methotrexate regardless of the treatment duration (even for only one month). Indeed, we wanted to test the worst hypothesis, by considering all cases of cancer diagnosed after the onset of methotrexate treatment as significant. As the data on the rheumatoid controls were only obtained from patients who had been admitted to hospital, the rheumatoid arthritis could be more severe in the control group than in the methotrexate group. It has been suggested that there is an increased risk of lymphoproliferative malignancy when rheumatoid arthritis is more severe. In fact, the rheumatoid arthritis was more active in the methotrexate treated patients, as shown in table 1 . Rheumatoid activity was not therefore a bias in interpreting the data in this study. Another important point is that, using the age adjusted incidence method, we noted the absence of any difference in the incidence of cancers when comparing each rheumatoid population to the regional population over two years (1991 and 1992). All these data suggest that methotrexate does not augment the incidence of cancer in rheumatoid arthritis. However, as the design of our study is not suited to evaluating the oncogenic potential of methotrexate, and as the follow up duration was short, especially in the control group, one must accept these results with caution. Clearly a longer term follow up is necessary to obtain more person-years at risk and also to answer the question about an increase in longer term risks. A good approximation of the numbers of patients required to show a statistical difference in the cancer occurrence in methotrexate treated and non-treated rheumatoid populations can be obtained using the comparison of two percentages. For the purpose of this calculation the following hypotheses were made: a cancer incidence of $1.88 \%$ in the methotrexate treated group as found in this study, a cancer incidence varying between $2 \%$ and $5 \%$ in the non-treated group (control) as previously published in different cohorts of rheumatoid arthritis patients, ${ }^{1-4}$ a bilateral test (no prior hypothesis on which type of rheumatoid arthritis population-treated with methotrexate or not - is exposed to a higher risk of cancer), and an $\alpha$ risk of $5 \%$. In this way, the expected number of patients with a $\beta$ risk of $20 \%$ (power of $80 \%$ ) varies between 424 and 2454 (cancer frequency in the non-treated group of $5 \%$ and $3 \%$ respectively). These numbers are respectively 679 to 3933 with a $\beta$ risk of $10 \%$ (power of $90 \%$ ).

Bailin et $\mathrm{l}^{30}$ previously showed that the incidence of cancer in 205 psoriatic patients treated with methotrexate was not significantly different from that expected in the general population. However, the presence of one case of lymphoma was higher than that theoretically expected $\left(0.2\right.$ case). Rustin et al ${ }^{31}$ studied the incidence of a second neoplasm in 457 patients treated with high doses of methotrexate for choriocarcinoma. The number of secondary cancers $(n=2)$ was lower than expected. McKendry and Dale reported on 144 rheumatoid arthritis patients treated with low doses of methotrexate $^{32}$ in a 13 year retrospective survey. They observed a 12 -fold increase in lung cancer $(n=4)$, but these patients were heavy cigarette smokers. The authors concluded that this increased incidence of lung cancer in the methotrexate treated rheumatoid population was probably a chance occurrence. ${ }^{32}$ In an important retrospective study, 39 out of a total of 16263 rheumatoid arthritis patients developed a haematological malignancy. ${ }^{33}$ Twelve had received methotrexate and 27 were never treated with this compound. Based upon the absence of specific histopathology of the haematologic malignancy in the methotrexate treated patients, the authors concluded that the risk from methotrexate is very small and does not appear to be related to cumulative doses of methotrexate or treatment duration. ${ }^{33}$

The small number of cancers occurring during methotrexate treatment in rheumatoid arthritis, their heterogeneous nature, and the absence of a higher incidence of cancer compared with that of rheumatoid controls and with the general population show that there is little chance that methotrexate is responsible for the generation of these cancers. Despite the difficulties in interpreting this study, the data presented here provide some reassurance for physicians on the use of methotrexate in rheumatoid arthritis. However, it is not possible to conclude that there is no risk with this drug on the basis of our study. Methotrexate could also be only a precipitating factor in the genesis of tumours. Longer prospective surveys of methotrexate treated rheumatoid patients compared to other rheumatoid patients not treated with methotrexate should be conducted to confirm this hypothesis. These studies should specifically target lymphomas, which are the most frequent neoplasms occurring in this situation and for which some intriguing data are reported. As it will be necessary to include a great number of patients in these prospective studies, a meta-analysis of the previously published studies could be another way in the future to answer this important question.

1 Matteson EL, Hickey AR, Maguire L, Tilson HH, Urowitz $\mathrm{MB}$. Occurrence of neoplasia in patients with rheumatoid arthritis in a DMARD registry. J Rheumatol 1991;18:80914.

2 Symmons DPM. Neoplasms of the immune system in rheumatoid arthritis. Am J Med 1985;78(suppl 1A):22-8.

3 Prior P. Cancer and rheumatoid arthritis: epidemiologic considerations. Am J Med 1985;78(suppl 1A):15-21.

4 Kinlen LJ. Incidence of cancer in rheumatoid arthritis and other disorders after immunosuppressive treatment. Am J Med 1985;78(suppl 1A):44-9.

5 Silman AJ, Petrie J, Hazleman B, Evans SJW. Lymphoproliferative cancer and other malignancy in patients with rheumatoid arthritis treated with azathioprine:a 20 year follow up study. Ann Rheum Dis 1988;47:988-92.

6 Colburn KK, Cao JD. Thymoma associated with rheumatoid arthritis in a patient taking methotrexate. J Rheumatol 1986;13:437-9.

7 Pointud P, Prudat M, Peron JM. Acute leukemia after low dose methotrexate therapy in a patient with rheumatoid arthritis. J Rheumatol 1993;20:1215-6.

8 Trenkwalder P, Eisenlohr H, Prechtel K, Lydtin H. Three cases of malignant neoplasm, pneumonitis, and pancytopenia during treatment with low-dose methotrexate. Clin penia during treatment

9 Shiroky JB, Frost A, Skelton JD, Haegert DG, Newkirk $M M$, Neville C. Complications of immunosuppression associated with weekly low dose methotrexate. J Rheumatol 1991;18:1172-5. 
10 Ellman MH, Hurwitz H, Thomas C, Kozloff M. Lymphoma developing in a patient with rheumatoid arthritis taking 18:1741-3.

11 Cobeta-Garcia JC, Ruiz-Jimeno MT, Fontova-Garrofe R. Non-Hodgkin's lymphoma, rheumatoid arthritis and methotrexate. J Rheumatol 1993;20:200-1

12 Le Goff P, Koreichi A, Saraux A, Baron D. Lymphome au cours du traitement de la polyarthrite rhumatoöde par le méthotrexate à faible dose: un nouveau cas. Rev Rhum Mal Osteoartic 1994;61:357-63.

13 Kamel OW, Van de Rijn M, Weiss LM, Del Zoppo GJ, Hench PK, Robbins BA, et al. Brief report: reversible lymphomas associated with Epstein-Barr virus occuring during methotrexate therapy for rheumatoid arthritis and dermatomyositis. N Engl J Med 1993;328:1317-21.

14 Morris CR, Morris AJ. Localized lymphoma in a patient with rheumatoid arthritis treated with parenteral methwith rheumatoid arthritis treated with
otrexate. J Rheumatol 1993;20:2172-3.

15 Kingsmore SF, Hall BD, Allen NB, Rice JR, Caldwell DS Association of methotrexate, rheumatoid arthritis and
lymphoma: report of 2 cases and literature review. J Rheulymphoma: report of 2

16 Cardon T, Heuschling C, Delaporte E, Cotten H, Catteau B, Farre JM, et al. Pseudolymphome cutané au cours d'une polyarthrite rhumatoïdetraitée par méthotrexate. Rev Rhum Mal Osteoartic 1994;61:740.

17 Lioté F, Pertuiset E, Cochand-Priollet B, D'Agay MF Dombret H, Numeric P, et al. Methotrexate related B lymphoproliferative disease in a patient with rheumatoid arthritis. Role of Epstein-Barr virus infection. J Rheumatol 1995;22:1174-8.

18 Zimmer-Galler I, Lie JT. Choroidal infiltrates as the initial manifestation of lymphoma in rheumatoid arthritis after treatment with low-dose methotrexate. Mayo Clin Proc 1994;69:258-61.

19 Bachman TR, Sawitzke AD, Perkins SL, Ward JH, Cannon GW. Methotrexate-associated lymphoma in patients with GW. Methotrexate-associated lymphoma in patients with

20 Taillan B, Garnier G, Ferrari E, Castanet J, Pesce, A, Fuzibet JG, et al. Lymphome malin au cours d'une polyarthrite ret JG, et al. Lymphome malin au cours d une polyarthrite rhumatoide traitee par de faibles doses de

21 Arnett FC, Edworthy SM, Bloch DA, McShane DJ, Fries $\mathrm{JF}$, Cooper NS, et al. The American Rheumatism Associa- tion 1987 revised criteria for the classification of rheumatoid arthritis. Arthritis Rheum 1988;31:315-24

22 Registre des tumeurs de l'Hérault. Le cancer dans l'Hérault. Association Registre des tumeurs de l'Hérault, Epidaure, Montpellier, France, 1989-1990 et 1991-1992.

23 Kerr LD, Troy K, Isola L. Temporal association between the use of methotrexate and development of leukemia in 2 patients with rheumatoid arthritis. J Rheumatol 1995; 22:2356-8

24 Kchir MM, Aloui S, Ben Taarit C, Hajri R, Karoui M, Zouari R, et al. Lymphome malin non-hodgkinien et polyarthrite rhumatoide. Sem Hop Paris 1992;68:1457-9.

25 Kassan SS, Thomas TL, Moutsopoulos HM, et al Kassan SS, Thomas TL, Moutsopoulos HM, et al. Increased risk of lymphoma
Intern Med 1978;89:888-92.

26 Holm LE, Blomgren H, Löwhagen T. Cancer risks in patients with chronic lymphocytic thyroiditis. N Engl J Med 1985;312:601-4

27 Kamel OW, Van de Rijn M, Lebrun DP, Weiss LM, Warnke RA, Dorfman RF. Lymphoid neoplasms in patients with rheumatoid arthritis and dermatomyositis: frequency of Epstein-Barr virus and other features associated with immunosuppression. Hum Pathol 1994;25:638- 43.

28 Castor CW, Bull FE. Review of United States data on neoplasms in rheumtoid arthritis. Am J Med 1985;78(suppl $1 \mathrm{~A}): 33-8$.

29 Lindskov R, Wulf HC, Wantzin GL, Niebuhr E. Sister chromatid exchange in patients treated with methotrexate for matid exchange in patients treated with me
psoriasis. J Invest Dermatol 1984;82:458-9.

30 Bailin PL, Tindall JP, Roenigk HH, Hogan MD. Is methotrexate therapy for psoriasis carcinogenic? A modified retrospective-prospective analysis. JAMA 1975; 232:359-62.

31 Rustin GJS, Rustin F, Dent J, Booth M, Salt S, Bagshawe $K D$. No increase in second tumors after cytotoxic chemotherapy for gestational trophoblastic tumors. N Engl J Med 1983;308:473-6.

32 McKendry RJR, Dale P. Adverse effects of low dose methotrexate therapy in rheumatoid arthritis. J Rheumatol 1993;20:1850-6.

33 Moder KG, Tefferi A, Cohen MD, Menke DM, Luthra HS. Hematologic malignancies and the use of methotrexate in rheumatoid arthritis: a retrospective study. Am J Med $1995 ; 99: 276-81$ 